\title{
Urdimento
}

Revista de Estudos em Artes Cênicas

E-ISSN: 2358.6958

\section{Teatro e Memória: Uma análise de Caranguejo Overdrive}

\author{
Gabriela Lírio Gurgel Monteiro
}

\section{Para citar este artigo:}

MONTEIRO, Gabriela Lírio Gurgel. Teatro e Memória:

Uma análise de Caranguejo Overdrive. Urdimento,

Florianópolis, v. 1, n. 40, mar./abr. 2021.

do) DOI: http:/dx.doi.org/10.5965/1414573101402021e0208

Este artigo passou pelo Plagiarism Detection Software | iThenticate 


\title{
Resumo
}

Gabriela Lírio Gurgel Monteiro

O que pode, nesse momento, as artes da cena? A imagem é a de um barco à deriva no oceano, no qual os tripulantes festejam a própria sorte (ou será a morte?), em um pacto coletivo no contrafluxo da vida. Com essa imagem, reflexo do momento político brasileiro, analiso Caranguejo Overdrive, dirigido por Marco André Nunes, com dramaturgia de Pedro Kosovski. Interessa investigar os motivos pelos quais foi censurado em 2019 e a relevância do debate sobre arte e memória histórica. Para isso, retomo o conceito de entrelugar do discurso latino-americano, desenvolvido por Silviano Santiago, em artigo dos anos 70, e sua revisitação quarenta anos depois, apontando para uma espiral do tempo, na qual o espetáculo nos convoca a retornar ao nosso mangue, a revolver nossos rastros e a reinventar o tempo que chega.

Palavras-chave: Memória. Entrelugar. História. Dramaturgia.

\section{Theater and Memory: An analysis of Caranguejo Overdrive}

\begin{abstract}
What can the performing arts do at that moment? The image is that of a boat adrift in the ocean, in which the crew celebrates their luck (or is it death?), in a collective pact in the counterflow of life. With this image, reflecting the Brazilian political moment, I analyze Caranguejo Overdrive, directed by Marco André Nunes, with dramaturgy by Pedro Kosovski. It is interesting to investigate the reasons why it was censored in 2019 and the relevance of the debate on art and historical memory. For this, I use the concept of "entre-lugar" in Latin American discourse, developed by Silviano Santiago, in an article from the 70s, and revisit forty years later, indicating to a spiral of time, in which the play calls us to return to our mangrove, revolving our traces and reinventing the time that comes.
\end{abstract}

Keywords: Memory. Entrelugar. History. Dramaturgy.

Professora Associada do Programa de Pós-Graduação em Artes da Cena (PPGAC) e do curso de Direção Teatral da Escola de Comunicação da Universidade Federal do Rio de Janeiro (ECO-UFRJ) gabilirio@yahoo.fr. (6) http://lattes.cnpq.br/5144170619756716

(iD) https://orcid.org/0000-0002-7466-960X 


\section{Resumen}

¿Qué pueden hacer las artes escénicas en ese momento? La imagen es la de un barco a la deriva en el océano, en el que la tripulación celebra su suerte (¿o es la muerte?), En un pacto colectivo en el contracorriente de la vida. Con esta imagen, reflejo del momento político brasileño, analizo el espectáculo Caranguejo Overdrive, dirigido por Marco André Nunes, con dramaturgia de Pedro Kosovski. Es interesante investigar las razones que fue censurada en 2019 y la relevancia del debate sobre arte y memoria histórica. Para ello, vuelvo al concepto de inter-lugares en el discurso latino-americano, desarrollado por Silviano Santiago, en un artículo de los años 70, y su revisita cuarenta años después, apuntando a una espiral del tiempo, en la que la muestra nos llama para volver a nuestro manglar, dando vueltas a nuestras huellas y reinventando el tiempo que llega.

Palabras clave: Memoria. Entre lugar. Historia. Dramaturgia. 
Dedico este ensaio à atriz Carolina Virgüez

Este ensaio nasce do convite do querido Prof. Dr. André Dias, em novembro de 2019, para participar de uma mesa na Universidade Federal do Rio Janeiro (UFF) ${ }^{2}$ cujo título era "Criação e encenação: exercícios de liberdade". Iniciava minha fala com as perguntas: Como criar em tempos de censura política? Como o teatro pode resistir e potencializar exercícios de liberdade hoje? Na ocasião eram mais de cinco espetáculos censurados no país, além de exposições e outras manifestações artísticas vistas como ameaça à ideologia do governo Bolsonaro. Ao conservadorismo e ao fascismo, destacava-se a resposta enérgica, dada pela classe artística, em ato político ${ }^{3}$, no dia onze de outubro de 2019, em frente ao Centro Cultural Banco do Brasil (CCBB), na Candelária, no Rio de Janeiro, rompendo o silêncio omisso da instituição que, inicialmente, sem qualquer explicação, cortou da pauta o espetáculo Caranguejo Overdrive, ganhador de diversos prêmios, dentre eles o Shell de melhor dramaturgia, direção e atriz. No momento da manifestação, o ccBB fechou suas portas e divulgou uma nota afirmando que "na encenação, [...] teriam sido acrescentados em seu roteiro posicionamentos político-partidários, com citação a nomes de personalidades políticas do atual governo e da oposição". A instituição dizia ainda que "o texto adicionado contrariaria critérios definidos no edital público para seleção de projetos e cláusulas contratuais do patrocínio, que vedam expressamente manifestações político-partidárias nos conteúdos a serem apresentados nos CCBBs" (Gobbi; Aragão, 2019).

Enquanto o Teatro Glauce Rocha, importante espaço cultural no Rio de Janeiro, era entregue por Roberto Alvim, secretário de Cultura à época, a um grupo evangélico, iniciativas como a do secretário de Cultura de São Paulo, Ale Youssef, de criar um festival com todos os espetáculos censurados surgiam como resposta.

\footnotetext{
${ }^{2}$ A mesa, composta por mim, pelo Prof. André Dias e pela atriz, produtora e diretora Rafaela Amado, foi parte integrante da IV Jornada do grupo de pesquisa "Literatura e Dissonâncias" (LIDIS), da Universidade Federal Fluminense (UFF).

${ }^{3}$ Ver https://oglobo.globo.com/cultura/cancelamento-de-caranguejo-overdrive-tema-de-protesto-ccbb-semanifesta-sobre-caso-24012698 Acesso em: 11 mar. 2021.
} 
Havia, naquele momento, pré-pandemia, a resistência presente em manifestações da classe artística e na ação de algumas instituições que, apesar de fragilizadas, afirmavam-se na luta pela liberdade de expressão e pela valorização da cultura no país. Na palestra, ressaltei a atenção para a necessidade de nos manifestarmos veementemente contra a censura, defendendo igualmente a importância das universidades públicas, alvo de ataque direto do governo, responsáveis por refletir sobre estratégias de resistência na tentativa de mobilizar um diálogo com a sociedade. Nesse momento, após um ano de pandemia, em que se somam mais de duzentos e cinquenta mil brasileiros mortos devido à ausência absoluta de política sanitária e com o notável crescimento de movimentos de extrema-direita que clamam pelo retorno do Al-5 e pelo fechamento das instituições, estamos diante de uma das maiores crises políticas de nosso país, senão a maior. A área da cultura também agoniza frente à falta de políticas para o setor nas instâncias municipal, estadual e federal. Perguntamo-nos como performar a própria história quando crianças e adolescentes, apesar da pandemia e de todas as perdas diárias, são assassinados diariamente em comunidades e mesmo dentro de suas casas? Como sobreviver ao caos de um genocídio sanitário representado por um presidente que, sem máscara de proteção, segura crianças no colo, abraça idosos em manifestações extremistas e afirma que, se vacinarmos, viramos jacaré? O que pode, nesse momento, as artes da cena? A imagem que tenho é a de um barco à deriva no oceano, no qual os tripulantes festejam a própria sorte (ou será a morte?), em um pacto coletivo no contrafluxo da vida.

Com essa imagem, reflexo da tragédia do momento político, gostaria de me deter na análise de Caranguejo Overdrive, de Aquela Cia. de Teatro, dirigido por Marco André Nunes, com dramaturgia de Pedro Kosovski ${ }^{4}$, refletindo sobre os motivos que a levaram a ser censurada. Inicialmente, retomo 0 entrelugar do discurso latino-americano (1971), de Silviano Santiago, recém editado na obra 35 Ensaios de Silviano Santiago, que reúne suas principais reflexões. Não à toa essa

${ }^{4}$ Com quatro indicações ao Prêmio Shell (nas categorias direção, texto, ator e atriz), quatro ao Prêmio Cesgranrio (melhor espetáculo, direção, texto e ator) e cinco ao Prêmio Questão de Crítica (melhor espetáculo, direção, texto, atriz e direção musical), Caranguejo Overdrive foi eleito um dos melhores espetáculos de 2015 pelo jornal O Globo e pela revista Veja. O espetáculo continua sua trajetória, tendo sido apresentado nos anos seguintes. 
reedição ocupa um espaço relevante de debate nesse momento, acenando para a espiral do tempo em que vivenciamos o retorno de regimes de direita e extremadireita em alguns países latino-americanos. Para Moriconi, organizador da obra, a "crítica de Santiago erige como princípio a valorização e análise da descontinuidade e da diferença em relação ao cânone" (Moriconi, 2019, p.11). Ao lançar mão do debate sobre o modernismo e do movimento antropofágico, busca provocar um deslocamento ou choque especulativo nas visões clássicas da dependência cultural..." (Moriconi, 2019, p.11). Na reflexão, desenvolvida no começo dos anos 70, Santiago retoma Barthes em $S / Z$, em sua interrogação antropófaga "que textos eu aceitaria escrever (reescrever), desejar, afirmar como uma força neste mundo que é o meu?"(Barthes apud Santiago, 2019, p.32). Citando as obras de Cortázar e Borges, afirma ainda que o escritor latino-americano nunca é inocente porque transita em um entrelugar: ao apropriar-se do discurso do colonizador, é capaz de realizar "um ritual antropófago" (Santiago, 2019, p. 37) deslizando em uma espécie de clandestinidade, "entre o sacrifício e o jogo, entre a prisão e a transgressão, entre a submissão ao código e a agressão, entre a obediência e a rebelião, entre a assimilação e a expressão..." (Santiago, 2019, p.37).

Caranguejo Overdrive propõe uma revisão histórica do continente, em uma luta contra as forças colonizadoras que subjugam e pretendem a aniquilação da alteridade em todos os seus aspectos, ligados à arte, à sexualidade, à defesa das diferenças de raça, gênero e classe social. Por este motivo, no momento da ascensão de forças de extrema-direita no país, o espetáculo sofreu censura, tendo sido excluído da pauta do CCBB, sem maiores explicações. Revisões históricas evidentemente não são bem-vindas, ao agirem na contramão do movimento perpetrado de disseminação de fakenews que tem por objetivo apagar fatos históricos importantes e esvaziar a possibilidade de reação coletiva. Diante de eventos traumáticos, como o que estamos vivendo, o resgate da memória histórica se faz necessário como uma "tarefa altamente política: lutar contra o esquecimento e a denegação é também lutar contra a repetição do horror (que, infelizmente, se reproduz constantemente)" (Gagnebin, 2009, p.47). Nesse sentido, é preciso reler o ensaio de Santiago, compreendendo as especificidades do 
percurso em que forças coloniais se desenvolveram no Brasil. O Congresso Nacional, na divisão das bancadas do "boi, da bíblia e da bala", é representante de um país que estruturalmente não avançou contra as desigualdades econômicas, o preconceito social e racial e as formas de violência e controle aos quais estamos submetidos. Por isso, a luta reside, também, na insistência de uma prática artística aliada à reflexão crítica; no questionamento do lugar que ocupa o artista latinoamericano; ainda que hoje, como afirma Moriconi, no lugar da utopia, vivamos o trauma.

Em Só mais um esforço (2018), Vladimir Safatle reflete sobre o papel do Brasil na América Latina pós-ditadura, afirmando que o país, diferentemente da Argentina e do Chile, foi o único a realizar "a profecia da violência sem trauma aparente" (p.64). Isso se deve à Lei da Anistia, que colocou lado a lado presos políticos e torturadores, favorecendo o desaparecimento e o apagamento, com a criação de "uma estrutura imóvel no tempo, resistente a toda e qualquer mudança, indestrutível. Um Leviatã descontrolado sob a capa do Estado de Direito" (p.65). Nesse sentido, faz-se necessário revolver nossa História e expor o trauma como ferida aberta.

\section{Decifrar os rastros e recolher os restos}

O ato de rememorar não se trata apenas de um resgate do passado, mas de uma ressignificação do presente; de uma ação sobre o presente. Ainda que, por meio da memória traumática ${ }^{5}$, não consigamos acessar algo da ordem do inenarrável, do indizível, de uma irrepresentabilidade, torna-se urgente que a narrativa seja simbolicamente transmitida na tentativa de não mais reproduzi-la. O potencial da arte e da cultura e, mais especificamente, do teatro, como

\footnotetext{
${ }^{5}$ É inevitável constatar que estamos diante de um momento da História absolutamente traumático, em que sofremos com perdas de todo tipo: desestruturação de famílias pela perda de entes queridos, aumento crescente da miséria em países menos desenvolvidos, com a perda de empregos e de condições mínimas de sobrevivência, falência de sistemas de saúde, perdas incontáveis na educação, problemática do desamparo psíquico, entre outros aspectos, que assemelham a pandemia a traumas sofridos em períodos de guerras. Sobre esta temática ver: Birman, 2020.
} 
instrumento de transformação da experiência traumática deve ser exaltado. As artes da cena são efêmeras, justamente porque trazem na sua forma de expressão a impossibilidade de uma repetição. Ainda que texto, atores, ações se repitam, é no encontro com o público que a experiência artística se constitui, e tal experiência existe justamente no instante desse encontro. Daí a memória teatral pertencer e renovar uma certa tradição oral e o sentido do ato de testemunhar. O espectador é testemunha do acontecimento cênico e, no caso de espetáculos cujas narrativas referem-se à história de um país, o ato de testemunhar, no qual o espectador se reconhece como parte dela, suscita não apenas a possibilidade de uma elaboração histórica, mas a ativação de uma política da memória, que ultrapassa o acontecimento artístico em si. A ideia do espectador como testemunha de um determinado momento histórico é recorrente no teatro, estando presente nas obras de Piscator, Brecht, Svoboda, Boal, Castellucci, Mroué, Mnouschkine e outros encenadores interessados em investigar a prática artística como transformadora da realidade política, por meio da reflexão histórica e da possibilidade de ressignificação do vivido.

Há o desafio permanente de seguir os rastros de um passado, "aprender a saber o que é o passado, como isso passou e em que medida se passou em nós e aí ficou travado" (Didi-Huberman, 2017, p.100). Didi-Huberman nos fala, no livro "Cascas", sobre a sua experiência (que não deixa de ser autoficcional), ao visitar o campo judeu de Auschwitz-Birkenau, e recolher pedacinhos de árvores, e fotografar vestígios da História, em como podemos interrogar as formas de transmissão da experiência traumática, rompendo com o clichê, escavando "o solo do tempo", "aprendendo a olhar os vestígios" (Didi-Huberman, 2017, p.100). A política da memória, afirma o autor, tem a ver com a política do desejo, o de ativar "nossos horizontes de expectativa e de esperança” (Didi-Huberman, 2017, p.100). Para isso, é preciso imaginar, escavar poeticamente, como ele tão bem o fez, na tentativa permanente de "decifrar os rastros e a recolher os restos" (Gagnebin, 2009, p.118).

No Brasil muitos rastros foram destruídos, os presos políticos assassinados e/ou desaparecidos. O país que anistiou torturadores hoje assiste ao discurso do 
Presidente da República que nega o golpe militar na ONU e cria uma narrativa de apagamento da história. Em 16 de maio de 2012, a ex-presidenta Dilma Roussef, em cerimônia no Palácio do Planalto, com a participação dos ex-presidentes Luiz Inácio Lula da Silva, Fernando Henrique Cardoso, Fernando Collor de Mello e José Sarney, instalou a Comissão Nacional da $\operatorname{Verdade}^{6}$ com o objetivo de resgatar a memória "sobre as graves violações de direitos humanos ocorridas no período anteriormente mencionado [1946-1988], contribuindo para o preenchimento das lacunas existentes na história de nosso país em relação a esse período e, ao mesmo tempo, para o fortalecimento dos valores democrático"(CNV, p.20). De acordo com o relatório final da Comissão Nacional da Verdade?:

ao examinar o cenário de graves violações de direitos humanos correspondente ao período por ela investigado, pôde constatar que ele persiste nos dias atuais. Embora não ocorra mais em um contexto de repressão política - como ocorreu na ditadura militar -, a prática de detenções ilegais e arbitrárias, tortura, execuções, desaparecimentos forçados e mesmo ocultação de cadáveres não é estranha à realidade brasileira contemporânea. Relativamente à atuação dos órgãos de segurança pública, multiplicam-se, por exemplo, as denúncias de tortura, o que levou à recente aprovação da Lei no 12.847/2013, destinada justamente à implementação de medidas para prevenção e combate a esse tipo de crime. É entendimento da CNV que esse quadro resulta em grande parte do fato de que o cometimento de graves violações de direitos humanos verificado no passado não foi adequadamente denunciado, nem seus autores responsabilizados, criando-se as condições para sua perpetuação (CNV, p. 964).

O relatório aponta que a tentativa de apagamento é um modo de interdição não apenas ao passado, mas se trata da reedição de práticas que violam sistematicamente os direitos humanos no Brasil. Por este motivo, é urgente que possamos ocupar o lugar de testemunhas de nossa própria história, uma vez que:

... testemunha também seria aquele que não vai embora, que consegue

\footnotetext{
${ }^{6}$ A Comissão Nacional da Verdade teve a participação dos seguintes membros: Claudio Fontelle, Gilson Dipp, José Carlos Dias, José Paulo Cavalcanti Filho, Maria Rita Kehl, Paulo Sergio Pinheiro, Pedro Dallari e Rosa Maria Cardoso da Cunha.

“A criação da Comissão Nacional da Verdade assegurará o resgate da memória e da verdade sobre as graves violações de direitos humanos ocorridas no período anteriormente mencionado [1946-1988], contribuindo para o preenchimento das lacunas existentes na história de nosso país em relação a esse período e, ao mesmo tempo, para o fortalecimento dos valores democráticos" (vol. 1, p. 20).
} 
ouvir a narração insuportável do outro e que aceita que suas palavras levem adiante, como num revezamento, a história do outro: não por culpabilidade ou por compaixão, mas porque somente a transmissão simbólica, assumida apesar e por causa do sofrimento indizível, somente essa retomada reflexiva do passado pode nos ajudar a não repeti-lo infinitamente, mas a ousar esboçar uma outra história, a inventar o presente (Gagnebin, 2009, p.57).

Reinventar o presente é prerrogativa do que vem ${ }^{8}$ se, no lugar de um pacto de morte coletiva ${ }^{9}$, nos abrirmos à escuta sensível da memória traumática. Contra - apagamento das narrativas históricas, é necessário desejar o conhecimento sobre o que se passou para, partindo dele, transmiti-lo, levá-lo adiante, ressignificá-lo; ressignificando também seus modos de transmissão. O que podem as artes da cena diante do genocídio, do fascismo, da barbárie? Como o ato artístico pode "transformar o real insuportável em experiência a partilhar ou transmitir?” "(Page, contra-capa, 2012). Como agir diante do ressentimento? Em "Figuras da história", Jacques Rancière afirma que o ressentimento dos homens visa a apagar a história, só se interessa pelo presente, pelo índice, uma espécie de tecido do real, odiando “...as imagens do passado” (Rancière, 2018, p.14). Na primeira parte do livro intitulada "O inesquecível", o autor investiga as relações entre memória e ficção no cinema documentário e ficcional. Segundo ele, há no movimento de captação da realidade, um “limiar entre o que interessa e o que não interessa ver" (Rancière, 2018, p.33). Entre o que a imagem revela e a palavra silencia, ou ainda, aquilo que a imagem torna invisível e a palavra surpreende, na afecção entre o visível e invisível, entre o dizível e o indizível, entre a ausência e a presença; nesse limiar, a arte atua criando efetivamente o acontecimento histórico e não apenas tendo como objetivo seu registro. "Entre uma ideia de história e uma potência da arte"(Rancière, 2018, p.48) está um movimento que privilegia situar o acontecimento "na atemporalidade de seu presente"(Rancière, 2018, p.47), dar voz ao inaudível, reescrever aquilo que subsiste, mas que não tem eco. Homens

\footnotetext{
${ }^{8}$ Retomo a distinção de Jacques Derrida entre o futuro e o "avenir", compreendendo a importância da obra de arte em se lançar diante do que não se sabe, diante do imprevisível, o que constitui em si mesmo a liberdade. 
enterrados vivos que sobrevivem à visão equivocada daqueles que, no lugar da vida, só vêem cadáveres. O que fazer dos nossos restos, é o que nos resta perguntar no Brasil da pandemia. Proponho a inversão com o objetivo de ressaltar que não se trata do transcurso da doença no país, mas de um país há muito doente.

\section{Caranguejo Overdrive: a antropofagia dos restos de um país}

O acontecimento traumático produz restos: um excesso indizível. (De Farias, 2008, p.101).

Dirigido por Marco André Nunes, com dramaturgia de Pedro Kosovski, Caranguejo Overdrive é um espetáculo que persegue os rastros e recolhe os restos, como alimento do caranguejo, animal resistente do Mangue que, ao se alimentar de matéria morta, putrefata, e dos restos de outros caranguejos, é resistente ao tempo e à ação nefasta do homem na natureza. O espetáculo rememora parte da história do Brasil e da cidade do Rio de Janeiro. Na dramaturgia de Kosovski, Cosme, um catador de caranguejo do Mangue é retirado pelo Exército brasileiro para lutar na guerra do Paraguai; quando retorna à cidade, não a reconhece, nem se reconhece, não é mais homem, seu corpo metamorfoseado é um corpocaranguejo. "Um caranguejo que um dia foi Cosme narra suas lembranças na Guerra do Paraguai" (Kosovski, 2016, p.31), uma guerra "branca”, higiênica” que arrastou 23 mil homens, a maior parte analfabetos, "um exército de escravos sem patriotismo", sem compreender em nome do que ou para quem se lutava, "índios, negros, escravizados, pobres, os excluídos da pátria” (Kosovski, 2016, p.33). Na guerra, Cosme, criado no mangue, catador de caranguejo, sobrevive à difteria, às fossas a céu aberto, à fome, à hipotermia, à cólera, à pneumonia que dizimou seus companheiros até ser vítima ele próprio de uma "explosão interna, uma síncope nervosa"10 (Kosovski, 2016, p.36) que o deixa paralisado, um corpo em choque que

10 Beribéri, depois sabemos. Doença típica dos escravos no Brasil Colônia, que consiste em um déficit nutricional causado pela falta de vitamina B1no organismo, provocando sintomas como: dificuldades respiratórias, fraqueza muscular e problemas gastrointestinais. 
o impede de continuar a matar e a se matar. O corpo de Cosme-caranguejo é um corpo animalizado, cindido, que inscreve no espaço sua estranheza diante de uma cidade violenta que não o acolhe, a cidade do Rio de Janeiro que, segundo ele, é "um corpo doente". Cosme-caranguejo-cidade atravessa no espetáculo um século em movimento de reatualização perene, da guerra do Paraguai à censura do CCBB, múltiplas temporalidades na batida frenética do Manguebeat, de Chico Science, tomando emprestada a inspiração na obra "Homens e Caranguejos" do geógrafo Josué de Castro"11, na carona do tropicalismo, do antropofagismo de Oswald de Andrade e das referências autobiográficas dos atores.

\section{Figura 1 - Ator Fellipe Marques em cena do espetáculo Caranguejo Overdrive} Foto: Elisa Mendes

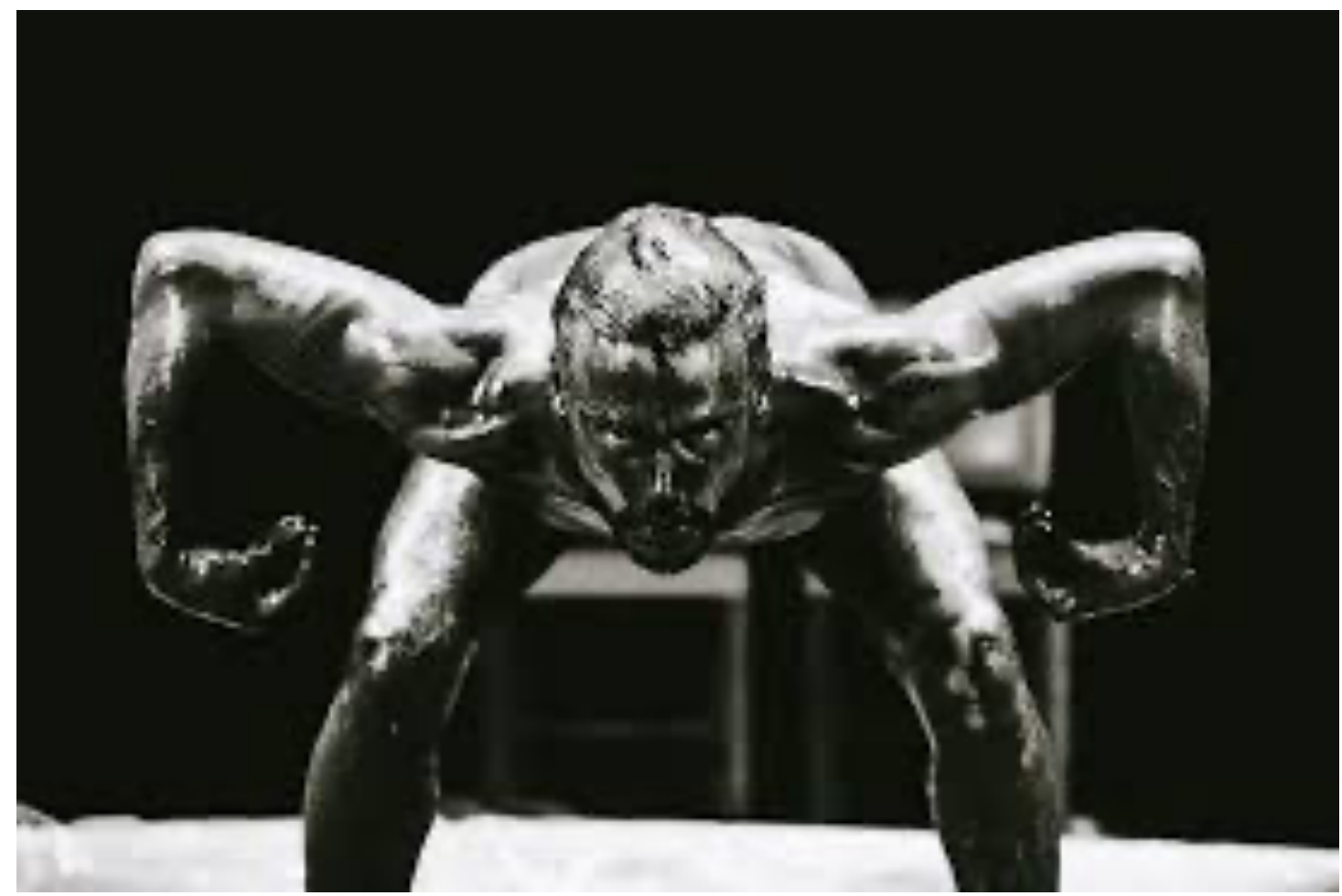

Acervo da fotógrafa

O Livro de Josué de Castro escrito em 1966 é, em parte, narrativa

11 "Josué de Castro, medico, geógrafo, escritor, pesquisador, professor e cientista social pernambucano (19081973), relata no prefácio do seu romance Homens e caranguejos, escrito em 1966, que logo na infância, em Recife, a descoberta da fome se revelou espontaneamente aos olhos dele. A convivência estreita de Josué com os caçadores de caranguejos nos mangues do Capibaribe, nos bairros miseráveis do Recife, é o ponto de partida do romance no qual Josué faz uma analogia entre homens e caranguejos."(Virgüez, 2019, p. 90). 
autobiográfica, inspirada na sua infância em Recife, na qual enxergou a fome ao conviver com os catadores de caranguejos no mangues do Rio Capibaribe. Nesse caldo "elétrico" e eletrizante da cultura brasileira, tendo a fome como norte, uma "fome que não é sentida no estômago, mas no espírito"(Kosovski, 2016, p.14), é que Cosme encontra a puta paraguaia, sua irmã latino-americana, imersa como ele "na guerra da cidade", raptada por um militar brasileiro que assassina toda a sua família. Como Cosme, ela vai parar no mangue, tempos depois aterrado para o surgimento da Avenida Presidente Vargas. Kosovski12 realizava uma pesquisa histórica sobre a urbanização do Rio de Janeiro, a construção do canal do Mangue, em 1857, na Praça 11, no momento dos Jogos Olímpicos na cidade, momento em que, também, muitas famílias foram violentamente removidas, como a comunidade da Vila Autódromo, na Zona Oeste.

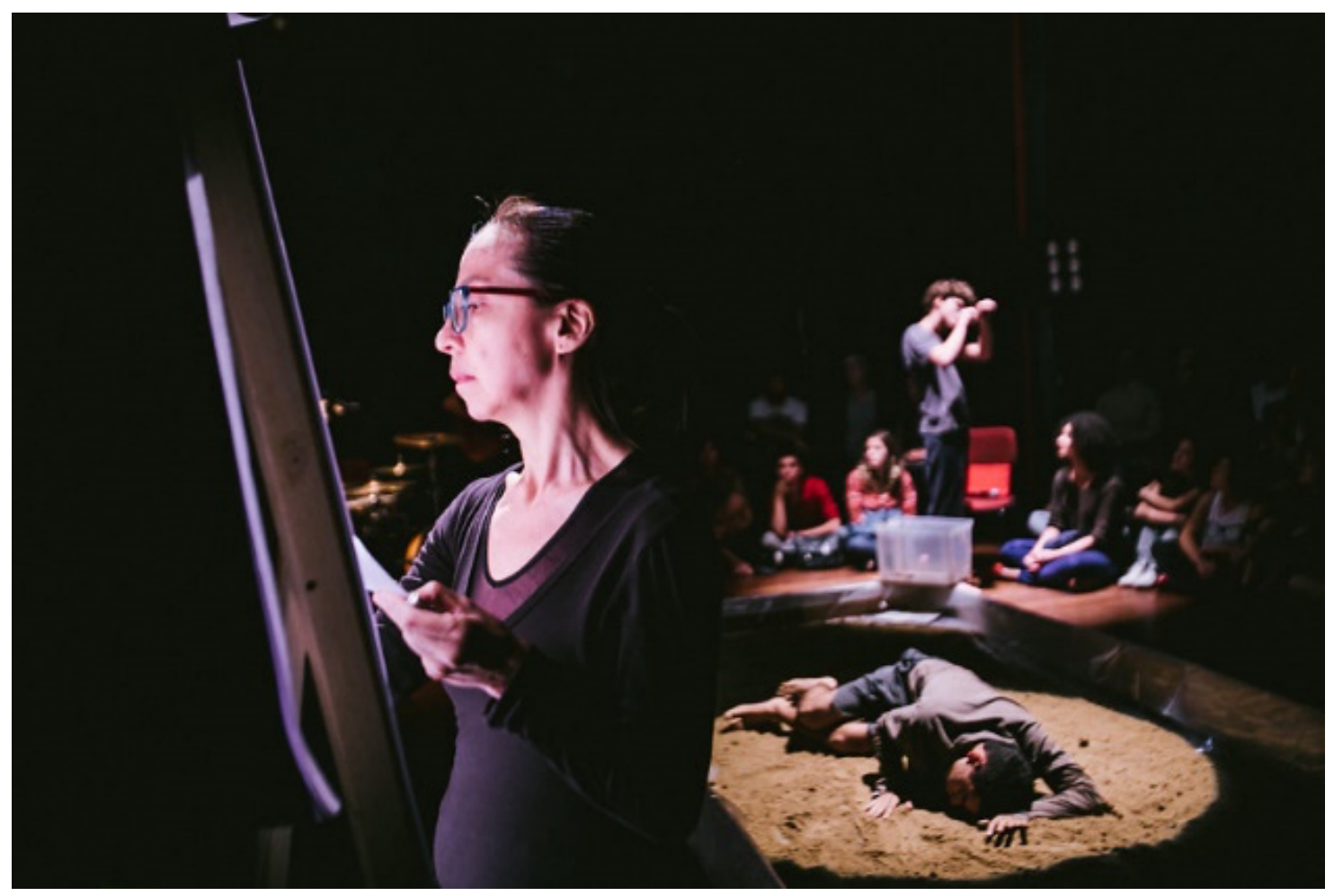

12 "Escrito para os 450 anos do Rio de Janeiro, em meio à disputa de territórios da cidade para a realização das Olimpíadas de 2016. Nesta peça, o território em disputa é o mangue, cuja extensão vai do Mangal de São Diogo (Rio de Janeiro, Cidade Nova, primeira metade do século XIX) até a obra do geógrafo Josué de Castro e o Manguebeat (Recife, décadas de 1960 e 1990)" (Kosovski, 2016, p.21). 
A puta paraguaia, representada pela atriz Carolina Virgüez, se oferece para ser guia turística de Cosme e apresenta em um fluxo ininterrupto, em um improviso, a história do Brasil. Em entrevista concedida a $\mathrm{mim}^{13}$, Carolina relata que o improviso veio de sua própria experiência. Ela também estrangeira que chega da Colômbia no Rio de Janeiro, em 1980; no espetáculo, não consegue "fechar "um texto, não consegue sequer escrevê-lo porque escrever seria, de certo modo, fixálo”. Seu depoimento dialoga com o que Santiago nomeia como sendo a destruição sistemática dos conceitos de unidade e de pureza"(Santiago, 2019, p.29): o trabalho de contaminação do discurso latino-americano vai na direção de um desvio da norma, um desvio "ativo e destruidor"(Santiago, 2019, p.29) em uma "geografia de aprendizagem e de reação" (Santiago, 2019, p.29). Nesse sentido, afirma Santiago, "falar, escrever, significa: falar contra, escrever contra".

Retomo o conceito de entrelugar de Santiago porque não é estático, continua sendo atravessado por várias forças, age por descontinuidade, deformação, deslocamento, pode ser pensado sob vários aspectos da cultura brasileira do século XXI. No ensaio “Silviano, autor de Derrida”, Eneida Maria de Souza investiga as relações não anacrônicas entre o pensamento de Santiago e de outros autores que influenciaram e dialogaram com sua obra, como Borges e Derrida. Ao se referir à criação do conceito de entre-lugar, Santiago (2001) afirma que:

Nunca fui vítima da lucidez racional da Europa como um novo Joaquim Nabuco, nem me deixei seduzir pelo espocar dos fogos de artifício ou pelas cores do carnaval nos trópicos. Fiquei com os dois e com a condição de viver e pensar os dois. Paradoxalmente. Nem o lugar comum dos nacionalismos brabos, nem o lugar-fetiche do aristocrata saber europeu. Lugar-comum e lugar-fetiche imaginei o entre-lugar e a solidariedade latino-americana. Inventei o entre-lugar do discurso latinoamericano que já tinha sido inaugurado pelos nossos melhores escritores. (Santiago, 2001, p. 434).

Refletir sobre transnacional hoje, em tudo o que já nos atravessou de lá para

${ }^{13}$ Assisti ao espetáculo no Espaço Sérgio Porto, no Rio de Janeiro, em outubro de 2019. No mesmo mês, entrevistei, por telefone, a atriz Carolina Virgüez, de quem há alguns anos acompanho o trabalho excepcional. Além disso, fui membro de sua banca de qualificação de mestrado, intitulada Inventário para o intangível: fuga para um fluxo improvisacional em Caranguejo Overdrive, em março de 2019, na Universidade Federal Fluminense (UFF). 
cá, o que significa o nacionalismo (e a bandeira brasileira que adquire uma nova significação, representando os ideais da extrema-direita brasileira) e como dialogamos com a alteridade é o que se propõe Caranguejo Overdrive. De certa forma, tudo isso ganha um novo sentido no espetáculo que atravessa nossa história desconstruindo também os clichês como, quando por exemplo, Carolina descreve o ex-presidente Collor, sua non-sense eleição e toda a tragédia que nos abateu naquele momento, inclusive o fim do Ministério da Cultura, que vimos mais uma vez ocorrer. A fala de Carolina se inscreve no corpo de sua personagem, a mulher-puta-latinoamericana, corpo verborrágico, fluxo ininterrupto de imagens absorvidas na pele e em sua vivência autoficcional no Brasil.

Acessei o meu corpo e voz dos anos 80, quando nasci no Brasil. Eu nem falava português. A puta era paraguaia. Estava improvisando em espanhol. Marco [o diretor] pediu para falar em espanhol. Eu, a puta paraguaia, a minha memória, ou a história do Brasil? Será que quem está falando é a história do Brasil com o meu corpo, a minha memória, e um ponto de vista que se desloca, ora para a puta, ora para mim? (Virgüez, 2019, p. 124).

O processo de criação da dramaturgia do espetáculo e o de criação dos atores ocorreram concomitantemente na sala de ensaio, a partir de uma concepção polifônica, na qual o corpo dos atores era foco do trabalho improvisacional. Um corpo coletivo, performativo e fragmentado pela trajetória histórica percorrida: da guerra do Paraguai, passando pelo mangue beat às remoções de comunidades às vésperas dos Jogos Olímpicos. Para a atriz, a memória do corpo a conduziu no processo: "Ao ser provocada por Marco e na iminência de sucumbir ali mesmo, pensei: eu não sei nada sobre esse período da história do Brasil, mas eu sei da história do Brasil que vivi, a que está na memória do meu corpo" (Virgüez, 2019, p. 119). Para ela, "a colonização e a subsequente relação de poder está no DNA do nosso corpo"(Virgüez, 2019, p.125). Corpo latinoamericano que busca a liberdade e que recusa a fome. Corpo que ocupa um entrelugar ao habitar o mangue que "é o encontro dos rios com o oceano. É o encontro entre a terra e o mar. É um lugar 'entre”' (Virgüez, 2019, p.122).

Ao apresentar a história do Brasil a Cosme, a puta paraguaia fala 
ininterruptamente articulando momentos dramáticos e hilários da história do Brasil, como o confisco da poupança no governo Collor, o impeachment de Dilma Rousseff, ou ainda, Itamar Franco acompanhado da modelo Lilian Ramos, sem calcinha, em plena Marques de Sapucaí. As imagens se intercalam em uma fala atravessada pela urgência e pela impotência diante de um país que saiu "dos trilhos"; um país que só pode ser compreendido em um movimento de ficcionalização da própria narrativa.

Entre a ficção e a vivência, entre o passado e o presente, entre o teatro e a vida, entre a atriz e a personagem. Entrelugar que nos constitui e provoca a emoção de Carolina, na manifestação contra a censura em frente ao CCBB, ao olhar a Avenida Presidente Vargas e a imaginar o grande mangue. Diante dos restos, soterrados pelo cimento da avenida de arquitetura europeia, de corpos negros escravizados e enterrados na região portuária ao lado, com sua voz de mulher latino-americana, ouço-a dizer que: Caranguejo Overdrive nos convoca a retornar ao nosso mangue, a revolver nossos rastros e a reinventar o tempo que chega.

\section{Referências}

BIRMAN, Joel. O trauma na pandemia do Coronavírus. Suas dimensões políticas, sociais, econômicas, culturais, éticas e científicas. Rio de Janeiro: Civilização Brasileira, 2020.

DE FARIAS, Francisco Ramos. Acontecimento traumático: fraturas da memória e descontinuidade histórica. In: As dobras da memória. Rio de Janeiro: 7Letras, 2008, p. 101-112.

DIDI-HUBERMAN, Georges. Cascas. São Paulo: Ed. 34, 2017.

GAGNEBIN, Jeanne Marie. Lembrar escrever esquecer. São Paulo: Ed. 34, 2009.

GOBBI, Nelson; ARAGÃO, Helena. Cancelamento de 'Caranguejo overdrive' é tema de protesto, e CCBB se manifesta sobre o caso. In: O Globo. Rio de Janeiro, 11/10/2019. Disponível em: https://oglobo.globo.com/cultura/cancelamento-decaranguejo-overdrive-tema-de-protesto-ccbb-se-manifesta-sobre-caso24012698?versao=amp Acesso em: 14 out. 2019. 
KOSOVSKI, Pedro. Caranguejo overdrive. Rio de Janeiro: Cobogó, 2016.

LEAL, Eneida Cunha. Uma literatura nos trópicos. Notas ao pé da página. In: Aletria, Belo Horizonte, v. 30, n. 1, p. 119-134, 2020.

MORICONI, Ítalo. Introdução. Critica, escrita, vida. In: 35 ensaios de Silviano Santiago. São Paulo: Companhia das Letras, 2019, p. 7-19.

PAGE, Christine (Org.). Écritures théâtrales du traumatisme. Esthétiques de la résistence. Rennes: Presses Universitaires de Rennes, 2012.

RANCIĖRE, Jacques. Figuras da história. São Paulo: Editora UNESP, 2018.

SAFATLE, Vladimir. Só mais um esforço. São Paulo: Três Estrelas, 2018.

SANTIAGO, Silviano. 35 ensaios de Silviano Santiago. São Paulo: Companhia das Letras, 2019.

VIRGÜEZ, Carolina Serrato. Inventário para o intangivel: fuga para um fluxo improvisacional em Caranguejo Overdrive. 2019. Dissertação (Mestrado em Estudos Contemporâneos das Artes) - Instituto de Arte e Comunicação Social, Universidade Federal Fluminense, Niterói, 2019.

Recebido em: 09/11/2020

Aprovado em: 19/03/2021 